\title{
Does ceramic translucency affect the degree of conversion of luting agents?
}

\author{
Ricardo Huver de Jesus ${ }^{1}$, Andrea Soares Quirino ${ }^{2,5}$, Vinicius Salgado ${ }^{3}$, Larissa Maria Cavalcante ${ }^{4,5}$, \\ William Mark Palin ${ }^{6}$ and Luis Felipe Schneider ${ }^{4,5,7^{*}}$
}

\author{
*Correspondence: \\ felipefop@gmail.com \\ ${ }^{7}$ Centro de Saúde Veiga \\ de Almeida, Núcleo de \\ Pesquisa de Biomateriais \\ Odontológicos, Praça da \\ Bandeira 149, Rio de Janeiro, \\ RJ CEP 20270-150, Brazil \\ Full list of author information \\ is available at the end of the \\ article
}

\begin{abstract}
Objectives: Solely light-activated luting agents have been suggested for cementing procedures with aesthetic rehabilitations, but questions remain regarding their curing potential under more opaque prosthesis. To determine the degree of carbon double bond $(C=C)$ conversion (DC) of four categories of luting strategies when considering the interposition of lithium-disilicate ceramic laminates with different translucencies during the photo-activation procedures.
\end{abstract}

Materials and methods: Four different luting strategies were considered: a dualactivated resin-based cement (control, RelyX ARC, 3M ESPE), a solely light-activated resin-based cement (RelyX Veneer, 3M ESPE), a flowable resin-based composite (Filtek Z350 XT Flow, 3M ESPE), and a pre-heated $\left(68^{\circ} \mathrm{C}\right.$ for $30 \mathrm{~min}$ ) regular resin-based composite (Filtek Z350 XT, 3M ESPE). The DC was determined by Fourier-transformed infrared spectroscopy $(n=6), 1$ min after light-activation in two conditions: (a) with direct light exposure and (b) with light exposure with the interposition of lithiumdisilicate disks (e.max Press, Ivoclar Vivadent) with $1.5 \mathrm{~mm}$ thickness with three translucent degrees: high translucency (HT), low translucency (LT), and medium opacity (MO). The translucency parameter (TP) formula was performed to quantitatively evaluate the ceramics' translucencies using white $\left(L^{*}=93.7, a^{*}=1.2\right.$, and $\left.b^{*}=0.8\right)$ and black $\left(L^{*}=8.6, a^{*}=-0.7\right.$, and $\left.b^{*}=-1.5\right)$ backgrounds. The irradiance from the light curing unit (Bluephase G2, Ivoclar Vivadent) was calculated with a power meter (Ophir Optronics) with direct light exposure to the sensor and also with the interposition of the light ceramic discs. Degree of conversion data was submitted to two-way ANOVA and Tukey's test $(a=0.05)$.

Results: Translucency parameters values were 16.4, 13.4 and 12.6 for HT, LT and MO ceramics - respectively - and affected the percentage of light transmission. For all ceramic translucencies the highest DC values were observed for the dual-activated resin-based cement followed by the solely light-activated resin-based cement, the flowable composite and then by pre-heated regular composite. The ceramic's translucency influenced the DC only for the pre-heated composite.

Conclusions: The effect of the ceramic translucency on the curing behavior was dependent on the luting strategy. The DC was only affected for the pre-heated composite, which demonstrates lower conversion with the increased ceramic opacity.

Keywords: Veneers, Dental materials, Prosthodontics, Luting resins 


\section{Introduction}

Lithium-disilicate-based dental ceramic restorations are commonly used for cosmetic and oral rehabilitation treatments. Various clinical applications for crowns, conventional veneers, ultra-thin veneers, occlusal veneers, and other partial dental restorations are justified due to the range of available translucencies, higher mechanical strength compared with more traditional feldspathic glass and the ability to modify fit surfaces that allows reliable adhesion with resin-based luting materials [1-4].

Optimal polymerization of the resin-based luting material is an important goal for the clinical success of lithium-disilicate-based restorations [5]. The degree of carbon double bond $(\mathrm{C}=\mathrm{C})$ conversion $(\mathrm{DC})$ is related to the mechanical properties of polymer-based materials where higher crosslink densities provide greater strength and stiffness. There are several factors of resin-based materials' composition that influence the DC as the inorganic content type, shape, and size; resin matrix type and amount; photoinitiator system type and amount. The DC determines the direct restorations' success, since lower monomer-polymer conversion corresponds to inferior mechanical properties and increased risk for leaching of toxic substances from the material [6-8]. During photoactivation of the luting agent, light is reflected at the surface and attenuated through the bulk of the ceramic material. The thickness and opacity of the lithium-disilicate ceramic is known to compromise polymerization of the resin-based luting composite [8-10]. However, studies regarding the effect of the ceramic interposition have focused mainly on traditional resin cements.

Different strategies have been proposed to bond lithium-disilicate-based restorations to the dental tissues. Usually, resin-based cements were indicated for this purpose, regardless of their activation mechanism, auto-, photo- or dual-activated materials $[8,10-12]$. Previous studies has suggested that dual-cure resin-based luting composites should be avoided where cosmetics are paramount since the high content of amine-based coinitiators in their composition may induce accelerated discoloration due to oxidation processes [13-15]. Therefore, alternative strategies have been considered.

Resin-based luting composites that are polymerized solely by light energy are popular amongst dental practitioners due to wide range of color and the possible application of "try in pastes", a water soluble-and easy to clean-glycerin-based paste that aims to reproduce the luting agent's shade. Therefore, it can be used for color matching tests and it easy to be removed before the final luting procedure with the proper resin cement. Alternatively, the use of so-called "flowable" resin-based composites with low viscosity has also been considered $[16,17]$ but this approach did not become so popular among clinicians. Further, pre-heating restorative resin-based composites that lowers viscosity have already been suggested for direct restorations [18, 19] due to higher conversion and improved mechanical properties. Pre-heated resinbased composites used for lithium-disilicate luting was also encouraged as fracture resistance and longevity of the restoration was improved [20]. However, besides been attractive concerning the color stability, the consequences of solely light-activated luting materials use for low-translucent lithium-disilicate are the unknown when regular restorative resin composites with regular viscosity are used with the pre-warmed technique. 


\section{Materials and methods}

\section{Objective}

To determine the influence of lithium-disilicate translucency on the degree of carbon double-bond conversion of various resin-based luting composites. The research hypothesis was that the degree of double-bond conversion would not be dependent on the lithium-disilicate translucency only for the dual-activated resin-based cement.

\section{Study design}

This in vitro, $3 \times 4$ factorial study design, involved three translucency degrees of lithium-disilicate ceramic and four luting agent types.

\section{Lithium-disilicate ceramic discs - optical properties and light irradiance attenuation}

Three lithium-disilicate ceramic disks ( translucencies, in A2 Shade (IPS e.max Press, Ivoclar-Vivadent, Schaan, Liechstenstein), were fabricated: high translucent (HT), medium opacity (MO) and low translucent (LT). The ceramic constituent information is provided in Table 1.

All disks were sintered according to the manufacturer's recommendations and by the same dental technician. To remove the irregularities, the surfaces finishing was carried out with polishing stone (EVE Diasync stones, Ernst Vetter GmbH) followed by graining polishing rubbers (EVE Diapol, Ernst Vetter $\mathrm{GmbH}$ ) pink, and gray, for $5 \mathrm{~s}$ each. A digital caliper with $0.01 \mathrm{~mm}$ resolution (Digimatic Caliper 0.01-150 mm, Mitutoyo, Tokyo, Japan) was used to check each disk thickness.

In order to quantitatively determine the translucency of each ceramic disk, they were placed over standardized white $\left(L^{*}=93.7, a^{*}=1.2\right.$, and $\left.b^{*}=0.8\right)$ and black $\left(L^{*}=8.6, a^{*}=-0.7\right.$, and $\left.b^{*}=-1.5\right)$ backgrounds (Ceramic Colour Standard, Ceram Research Ltd., Stoke-on-Trent, Staffordshire, United Kingdom) for color measurement analysis, using an intraoral spectrophotometer (VITA Easyshade Compact, VITA Zahnfabrik, Germany) in reflectance mode and the L*a*b* color space [21]. The equipment was previously calibrated in its calibration block according to the manufacturer's instructions. The probe tip ( $\varnothing 5 \mathrm{~mm}$ ) was placed perpendicularly, and flush, to each disk surface and the average of three measurements were recorded. In the $L * a^{*} b^{*}$ color space, the $L *$ parameter represents the lightness, where 100 is white and 0 is black, while the $a^{*}$ and the $b^{*}$ parameters represents the red-green and yellowblue chromaticity coordinates respectively. Thus, the translucency parameter (TP) formula was used [22]:

$$
\mathrm{TP}=\left[\left(\mathrm{L}_{\mathrm{w}}^{*}-\mathrm{L}_{\mathrm{b}}^{*}\right)^{2}+\left(\mathrm{a}_{\mathrm{w}}^{*}-\mathrm{a}_{\mathrm{b}}^{*}\right)^{2}+\left(\mathrm{b}_{\mathrm{w}}^{*}-\mathrm{b}_{\mathrm{b}}^{*}\right)^{2}\right]^{1 / 2}
$$

where "w" refers to the $L^{*}, a^{*}$, and $b^{*}$ parameters values for each lithium-disilicate disk measured over the white background and " $b$ " over the black.

The diameter of the light curing unit at (Bluephase G2, Ivoclar Vivadent, Liechtenstein) tip was measured with a digital caliper (Mitutoyo, Japan) to calculate the effective tip area in $\mathrm{cm}^{2}$. The power $(\mathrm{mW})$ was then measured using a power meter (Ophir 10A-V2-SH, Har-Hotzvim, POB 45021, Jerusalem 91450, Israel) connected to 
Table 1 Tested materials constituent information

\begin{tabular}{|c|c|c|c|}
\hline Luting agents & Inorganic content fraction & Organic matrix & Activation system \\
\hline RelyX ARC & $\begin{array}{l}\text { Silane treated silica and } \\
\text { silane treated ceramic } \\
72 \text { wt } \%\end{array}$ & $\begin{array}{l}\text { Paste A: BisGMA, TEGDMA, } \\
\text { functionalized dimeth- } \\
\text { acrylate polymer, 2-benzo- } \\
\text { triazolyl-4-methylphenol, } \\
\text { 4-(dimethylamino)-Benze- } \\
\text { neethanol } \\
\text { Paste B: TEGDMA, BisGMA, } \\
\text { functionalized dimeth- } \\
\text { acrylate polymer, 2-benzo- } \\
\text { triazolyl-4-methylphenol, } \\
\text { benzoyl peroxide }\end{array}$ & Dual-activated \\
\hline RelyXVeneer & $\begin{array}{l}\text { Zirconia/silica and fumed } \\
\text { silica fillers } \\
66 \text { wt } \% \text { ( } 0.6 \mathrm{~mm} \text { average } \\
\text { filler size) }\end{array}$ & $\begin{array}{l}\text { (BisGMA) and (TEGDMA) } \\
\text { polymer }\end{array}$ & Photo-activated \\
\hline Filtek Z350 XT Flow & $\begin{array}{l}\text { Zirconia/silica cluster filler } \\
\text { and } 20 \mathrm{~nm} \text { silica filler } \\
65 \mathrm{wt} \%\end{array}$ & $\begin{array}{l}\text { bis-GMA, TEGDMA, and } \\
\text { bis-EMA }\end{array}$ & Photo-activated \\
\hline Filtek Z350 XT & $\begin{array}{l}\text { Non-agglomerated/non- } \\
\text { aggregated } 20 \text { nm silica } \\
\text { filler, non-agglomerated/ } \\
\text { non-aggregated } 4 \text { to } \\
11 \mathrm{~nm} \text { zirconia filler, and } \\
\text { aggregated zirconia/silica } \\
\text { cluster filler (comprised } \\
\text { of } 20 \text { nm silica and } 4 \text { to } \\
11 \mathrm{~nm} \text { zirconia particles) } \\
\text { average cluster particle size } \\
\text { of } 0.6 \text { to } 10 \text { microns } \\
78.5 \% \text { by weight }\end{array}$ & $\begin{array}{l}\text { bis-GMA, UDMA, TEGDMA, } \\
\text { and bis-EMA }\end{array}$ & Photo-activated \\
\hline Lithium-disilicate ceramics & \multicolumn{2}{|l|}{ Crystal phase } & \\
\hline \multirow[t]{3}{*}{ IPS e.max press high translucenc) } & \multirow[t]{3}{*}{$\begin{array}{l}\text { Lithium disilicate crystals } \\
\text { (approx. 70\%) }\end{array}$} & \multirow[t]{3}{*}{$\begin{array}{l}\text { Needle-like crystals } \\
\text { length }\end{array}$} & 3 to $6 \mu \mathrm{m}$ in \\
\hline & & & \\
\hline & & & \\
\hline
\end{tabular}

BisGMA bisphenol-A-diglycidylether dimethacrylate, TEGDMA triethylene glycol dimethacrylate, BisEMA bisphenolpolyethylene glycol dimethacrylate, UDMA urethanethyl dimethacrylate

a microprocessor (Ophir, Har-Hotzvim, POB 45021, Jerusalem 91450, Israel). Measurements were performed with the light tip juxtaposed to the power meter sensor and with the interposition of each ceramic disc. A black tape was used to surrounding area and avoid light dispersion trough any casual small gap between the light tip and the ceramic disc. Light irradiance (in $\mathrm{mW} / \mathrm{cm}^{2}$ ) was determined by the ratio between power (in $\mathrm{mW}$ ) by the area $\left(\mathrm{cm}^{2}\right)$. Additional readings were done with the Mylar strip between the light tip and the ceramic discs, but the difference was irrelevant.

\section{Luting agents}

Four types of luting agents in A1 shade were selected for this study as shown in Table 1, a dual-activated resin-based cement (D-AC; RelyX ARC, 3M ESPE, St Paul, USA) selected as control, a photo-activated resin-based cement (P-AC; RelyX Veneer, 3M ESPE, St Paul, USA), a flowable resin-based composite (FRBC; Filtek Z350 XT Flow, 3M ESPE, St Paul, USA), and a pre-heated conventional resin-based composite (P-HRBC; Filtek Z350 XT, 3M ESPE, St Paul, USA). The conventional resin-based composite restorative 
Table 2 Lithium-disilicate discs' CIELAB parameters values over the white $(w)$ and black (b) backgrounds, the correspondent translucency parameters (TP) and light irradiance values with the ceramic discs' interpositions

\begin{tabular}{|c|c|c|c|c|c|}
\hline \multirow[t]{2}{*}{ Lithium-disilicate translucency } & \multicolumn{4}{|c|}{ Optical properties } & \multirow{2}{*}{$\begin{array}{l}\text { Light irradiance (Direct light } \\
\left.\text { irradiance }=1218 \mathrm{~mW} / \mathrm{cm}^{2}\right) \text { in } \mathrm{mW} / \mathrm{cm}^{2}(\% \\
\text { of light maintenance) }\end{array}$} \\
\hline & $L^{*}$ & $a^{*}$ & $b^{*}$ & TP & \\
\hline \multirow[t]{2}{*}{ High translucency $(\mathrm{HT})$} & $94.0_{w}$ & $0.7_{w}$ & $14.8_{w}$ & 16.4 & $810(66 \%)$ \\
\hline & $78.8_{\mathrm{b}}$ & $-0.8_{b}$ & $8.8_{\mathrm{b}}$ & & \\
\hline \multirow[t]{2}{*}{ Low translucency (LT) } & $89.7_{w}$ & $1.3_{w}$ & $22.6_{w}$ & 13.4 & $692(57 \%)$ \\
\hline & $79.2_{b}$ & $-0.6_{b}$ & $15.1_{b}$ & & \\
\hline \multirow[t]{2}{*}{ Medium opacity (MO) } & $83.6_{w}$ & $4.0_{w}$ & $38.4_{w}$ & 12.6 & $566(46 \%)$ \\
\hline & $76.4_{b}$ & $0.5_{b}$ & $28.7_{b}$ & & \\
\hline
\end{tabular}

Values are average of three measurements performed

material was inserted in a "centrix tube" and the set (the tube already attached to the syringe, Nova DFL, Rio de Janeiro, Brazil) was placed heated in an oven to $68 \pm 1{ }^{\circ} \mathrm{C}$ for 30 min to reduce the viscosity [19].

\section{Degree of $\mathrm{C}=\mathrm{C}$ conversion}

The degree of $\mathrm{C}=\mathrm{C}$ conversion $(\mathrm{DC})$ was determined by Fourier-transform infrared spectroscopy $(n=6)$ [23], using a spectrometer equipped with an attenuated total reflectance (ATR) diamond device (Alpha, Bruker, Germany). A black circular plastic mold (0.3 mm thickness, $7 \mathrm{~mm}$ inner diameter) was centrally positioned over the ATR crystal and slightly overfilled with the luting materials. A Mylar strip was placed above the resin composite and flattened using the lithium-disilicate disk. After the placement of each material, an Infrared (IR) monomer spectrum was obtained using 32 scans and $4 \mathrm{~cm}^{-1}$ resolution. With the lithium-disilicate disk interposition, each luting material was photo-activated for $40 \mathrm{~s}$. Then, the second IR spectrum was obtained 5 min after postirradiation. The DC (\%) was calculated with the following formula:

$$
\% \mathrm{DC}=100 \times\left\{1-\left[\frac{\left(\mathrm{C}=\mathrm{C}_{\text {cured }} / \text { aromatic }_{\text {cured }}\right)}{\left(\mathrm{C}=\mathrm{C}_{\text {uncured }} / \text { aromatic }_{\text {uncured }}\right)}\right]\right\} .
$$

The calculation considered the differences in intensity of $\mathrm{C}=\mathrm{C}$ stretching vibration (peak area) at $1638 \mathrm{~cm}^{-1}$ of the uncured and cured spectra. The symmetric aromatic stretching at $1608 \mathrm{~cm}^{-1}$ (peak area) was used as internal standard. For each luting agent, the DC was determined without and with each lithium-disilicate disk interposition.

\section{Statistical analysis}

The statistical analyses were conducted using SigmaPlot ${ }^{\circledR} 13.0$ software (Systat Software). Data for the DC were analyzed by two-way analysis of variance, considering "lithium-disilicate translucency" and "resin-based luting composite" as factors. All pairwise multiple comparisons procedures were performed using the Tukey's test $(\alpha=0.05)$. 
Table 3 Results of the degree of $C=C$ conversion in percentage (\% DC) depending of the different lithium-disilicate translucencies interposition during photo-activation

\begin{tabular}{lllll}
\hline Luting composite & $\begin{array}{l}\text { DC after direct } \\
\text { light activation }\end{array}$ & \multicolumn{2}{l}{ DC with light activation trough the ceramic discs } \\
\cline { 3 - 5 } & & $\begin{array}{l}\text { High translucency } \\
\text { (HT) }\end{array}$ & $\begin{array}{l}\text { Low translucency } \\
\text { (LT) }\end{array}$ & $\begin{array}{l}\text { Medium opacity } \\
\text { (MO) }\end{array}$ \\
\hline $\begin{array}{l}\text { Dual-activated resin- } \\
\text { based cement (con- } \\
\text { trol) (RelyX ARC) }\end{array}$ & $80.5 \pm 0.9^{\mathrm{Aa}}$ & $82.9 \pm 1.3^{\mathrm{Aa}}$ & $80.3 \pm 0.7^{\mathrm{Aa}}$ & $83.9 \pm 0.8^{\mathrm{Aa}}$ \\
$\begin{array}{l}\text { Photo-activated resin- } \\
\text { based cement (RelyX }\end{array}$ & $73.9 \pm 3.2^{\mathrm{Ab}}$ & $74.1 \pm 2.7^{\mathrm{Ab}}$ & $73.3 \pm 5.7^{\mathrm{Ab}}$ & $74.6 \pm 2.0^{\mathrm{Ab}}$ \\
$\begin{array}{l}\text { Veneer) } \\
\text { Flowable resin-based } \\
\text { composite (Filtek } \\
\text { Z350 XT Flow) }\end{array}$ & $68.9 \pm 2.5^{\mathrm{Ac}}$ & $67.9 \pm 1.5^{\mathrm{Ac}}$ & $65.4 \pm 2.3^{\mathrm{Ac}}$ & $67.4 \pm 3.8^{\mathrm{Ac}}$ \\
$\begin{array}{l}\text { Pre-heated conven- } \\
\text { tional resin-based } \\
\text { composite (Filtek }\end{array}$ & $65.3 \pm 3.2^{\mathrm{Ac}}$ & $60.6 \pm 2.3^{\mathrm{Bd}}$ & & \\
Z350 XT) & & & & \\
\hline
\end{tabular}

Values are means \pm standard deviations $(n=6)$

In \% DC column, distinct capital letters indicate significant difference among the different ceramic translucencies for each luting composite while distinct lowercase letters indicate significant difference among the luting composites for each ceramic translucency $(a=0.05)$. Significance values were: $p<0.001$ for the luting composite, $p=0.010$ for the ceramic translucency, and $p=0.001$ for the interaction between the luting composite and the ceramic translucency

\section{Results}

The obtained TP values were 16.4 for HT, 13.4 for LT, and 12.6 for MO. The correspondent $L^{*} a^{*} b^{*}$ color space data are presented at Table 2. Table 2 also demonstrates the information provided by the analyses performed with the power meter. The light irradiance value obtained with direct exposure to the sensor was $1218 \mathrm{~mW} / \mathrm{cm}^{2}$ and reduced to 810,692 and $566 \mathrm{~mW} / \mathrm{cm}^{2}$ with the interposition of HT, LT and MO ceramic discs, respectively.

The DC values are described in Table 3. Considering the ANOVA evaluation, the lithium-disilicate translucency effect over the final DC was not statistically significant $(p=0.112)$. On the other hand, the effect of the resin-based luting composite $(p<0.001)$, as well as the interaction between these two factors $(p=0.002)$ were statistically significant. Considering the influence of the different lithium-disilicate translucencies over DC values, no significant differences among the HT, LT, and MO were observed for all materials except for P-HRBC $(\mathrm{p}<0.001)$. Significantly different DC values were observed among the luting composite materials. For all different lithium-disilicate translucencies ( $\mathrm{p}<0.05$ for LT, HT, and MO), the D-AC showed the highest values, followed for the $\mathrm{P}-\mathrm{AC}$, then by the FRBC, and then by the P-HRBC, which presented the lowest values.

\section{Discussion}

For all ceramic restorations, the final physical properties of the resin-based luting material may determine the clinical success [24]. Therefore, in theory, a low monomer-polymer conversion could correspond to reduced mechanical and color stabilities, ultimately leading to premature clinical failures. Considering the analysis of variance results the DC was not dependent on the lithium-disilicate translucency and, consequently, the 
research hypothesis was rejected. However, it is important to mention the exception observed with the pre-heated conventional resin-based composite.

It should be expected that the ceramic translucency would directly affect the degree of $\mathrm{C}=\mathrm{C}$ conversion [25] but this was not a general trend in the current study. This could be explained by the fact that the ceramic samples thickness was reduced and therefore, the optical differences among those materials were not enough to promote distinct light attenuation or not within a scale that provides distinct data. Another explanation could be related to the fact that a very powerful LED light curing unit was used and sufficient energy was delivered to the tested materials besides the effect of light attenuation. As seen in Table 1, at least $566 \mathrm{~mW} / \mathrm{cm}^{2}$ was able to achieve the luting materials in the worst case scenario (with the MO translucency), and by using $40 \mathrm{~s}$ of light exposure it was enough to provide more than $22 \mathrm{~J} / \mathrm{cm}^{2}$. These outcomes corroborate with Faria-e-Silva and Pfeifer [10] that performed an in vitro study to determine the effectiveness of high-power LEDs to polymerize visible light-activated resin cement through ceramics and concluded that the ceramic interposition had only a slight effect on polymerization kinetics. In this study, the authors also detected that the ceramic interposition had some effect over the final DC only when ceramic discs with $1.5 \mathrm{~mm}$ thickness were used. It is also important to remember that only lithiumdisilicate-based ceramics were tested in the current study and that similar behavior could not be expected when other ceramic types or even indirect composites are used. In example, recent studies have demonstrated that the zirconia type might influence the final DC of some luting agents as well as the consequent properties [26-28].

Pre-heated regular composites have been suggested for different clinical applications, such as to improve the handling characteristics for direct restorations or to become fluid enough to serve as a proper luting agent [29, 30]. In vitro investigations have demonstrated that pre-heated composites might have some benefits. Gresnigt et al. [20] found that luting of lithium disilicate laminate veneers by pre-heated regular composite (Enamel HFO, Micerium) resulted in higher survival and fracture resistance than a regular resin cement (Variolink Esthetic LC, Ivoclar Vivadent). This behavior could be related to the filler content, which is higher for regular composites. Additionally, greater conversion of monomers could be obtained and requiring reduced light exposure than with room-temperature composites due to greater mobility at the initial stages [31]. Such behavior was not observed in the current study and the DC of pre-heated regular composite was affected by the ceramic interposition and at this point it is important to clarify that the rheological behavior of pre-heated composites is material-brand dependent [32].

The current investigation considered the use of Filtek Z350 XT (Filtek Supreme XT in some countries) to keep the same manufacturer from the resin cements and, therefore, to reduce part of the variations resultant from large differences that exists among the formulations from different companies. Al-Ahdal et al. [32] analyzed the rheological properties of resin composites according to variations in composition and temperature and demonstrated that Filtek Z350 XT exhibited the highest viscosity both at $25{ }^{\circ} \mathrm{C}$ and $37{ }^{\circ} \mathrm{C}$. Considering the outcomes from the present investigation, it can be speculated that the very high content of Filtek Z350 XT makes it more dependent on the amount of reaching light due to the light scattering effect and might explain 
why pre-heated composite was the only material affected by the ceramic translucency when considering the pairwise comparisons.

Although the current investigation brings important data for the current knowledge, it is important to consider some limitations and future directions:

- Besides the composite was pre-heated at $68 \pm 1{ }^{\circ} \mathrm{C}$, the real temperature at the moment of the activation was probably much lower due to cooling effect caused by the contact both with the ceramic veneer and also the ATR crystal that were kept at room temperature as it took $\approx 90 \mathrm{~s}$ from the removal from the oven to the end of the FTIR reading. Although this represents a real clinical situation, the temperature reduction impairs proper molecular diffusion and, thus, degree of $\mathrm{C}=\mathrm{C}$ conversion [33]. Consequently, further studies have now been conducted to determine the effect of pre-heating both different material brands and, also, the effect of the laminate veneer temperatures on the degree of $\mathrm{C}=\mathrm{C}$ conversion.

- The current investigation considered the degree of $\mathrm{C}=\mathrm{C}$ conversion after $5 \mathrm{~min}$ and it is crucial to determine the post-curing after a long period of time.

- Degree of conversion is an important aspect, but experiments aiming to analyze both the mechanical properties, stress development and the degradation resistance are crucial.

\section{Conclusions}

Based on the results of this study it can be concluded that the degree of $\mathrm{C}=\mathrm{C}$ conversion was not influenced by the different lithium-disilicate translucency for any luting agent, except for the pre-heated conventional resin-based composite which presented significant lower conversion.

\section{Abbreviations}

C=C: Carbon double bond; DC: Degree of conversion; HT: High translucency; LT: Low translucency; MO: Medium opacity; TP: Translucency parameter; $\mathrm{cm}^{2}$ : Square centimeter; $\mathrm{mW}$ : Milliwatt; $\mathrm{mW} / \mathrm{cm}^{2}$ : Milliwatt/square centimeter; D-AC: Dual-activated resin-based cement; P-AC: Photo-activated resin-based cement; FRBC: Flowable resin-based composite; P-HRBC: Pre-heated conventional resin-based composite; ATR: Attenuated total reflectance; FTIR: Fourier transform infrared; IR: Infrared spectrum; ${ }^{\circ} \mathrm{C}$ : Celsius; mm: Millimeter; LED: Light-emitting diode; J/ $\mathrm{cm}^{2}$ : Joules/square centimeter.

Acknowledgements

Authors are grateful to FUNADESP and FAPERJ JCNE for research scholarships.

\section{Authors' contributions}

LFS conceived and designed this study. ASQ, RH and VS performed the experiments. RH, VS and LFS analyzed and interpreted the data. LSF, LC and WP reviewed the manuscript. All authors read and approved the final manuscript.

\section{Funding}

This research was funded by Fundação de Amparo à Pesquisa do Estado do Rio de Janeiro (FAPERJ) (E-26/202.735/2018), Young Scientist Program.

\section{Availability of data and materials}

All relevant data is presented in the manuscript and additional information can be made available on request if necessary.

\section{Competing interests}

The authors declare that they do not have competing interests.

\section{Author details}

1 School of Dentistry, Faculdade Multivix, Rua José Alves 135, Vitória, ES CEP 29075-080, Brazil. ${ }^{2}$ School of Dentistry, Universidade Federal do Rio de Janeiro, Rio de Janeiro, Brazil. ${ }^{3}$ Private Practice, Rio de Janeiro, RJ, Brazil. ${ }^{4}$ School of Dentistry, Federal Fluminense University, Niteroi, RJ, Brazil. ${ }^{5}$ Nucleus for Dental Biomaterials Research, Veiga de Almeida University, 
Praça da Bandeira 149, Rio de Janeiro, RJ 20270-150, Brazil. ${ }^{6}$ Biomaterials Unit, School of Dentistry, Institute of Clinical Sciences, College of Medical and Dental Sciences, University of Birmingham, Birmingham, UK. ${ }^{7}$ Centro de Saúde Veiga de Almeida, Núcleo de Pesquisa de Biomateriais Odontológicos, Praça da Bandeira 149, Rio de Janeiro, RJ CEP 20270-150, Brazil.

Received: 16 December 2019 Accepted: 17 April 2020

Published online: 25 April 2020

\section{References}

1. Layton DM, Clarke M. A systematic review and meta-analysis of the survival of non-feldspathic porcelain veneers over 5 and 10 years. Int J Prosthodont. 2013;26(2):111-24. https://doi.org/10.11607/ijp.3202.

2. Gresnigt MM, KalkW, Özcan M. Clinical longevity of ceramic laminate veneers bonded to teeth with and without existing composite restorations up to 40 months. Clin Oral Investig. 2013;17:823-32. https://doi.org/10.1007/s0078 4-012-0790-5.

3. Miranda ME, Olivieri KA, Rigolin FJ, Basting RT. Ceramic fragments and metal-free full crowns: a conservative esthetic option for closing diastemas and rehabilitating smiles. Oper Dent. 2013;38:567-71. https://doi.org/10.2341/12-225-T.

4. Sasse M, Krummel A, Klosa K, Kern M. Influence of restoration thickness and dental bonding surface on the fracture resistance of full-coverage occlusal veneers made from lithium disilicate ceramic. Dent Mater. 2015;31:907-15. https ://doi.org/10.1016/j.dental.2015.04.017.

5. Moraes RR, Correr-Sobrinho L, Sinhoreti MA, Puppin-Rontani RM, Ogliari FA, Piva E. Light-activation of resin cement through ceramic: relationship between irradiance intensity and bond strength to dentin. J Biomed Mater Res B Appl Biomater. 2008;85:160-5. https://doi.org/10.1002/jbm.b.30928.

6. Rasetto FH, Driscoll CF, Prestipino V, Masri R, Von Fraunhofer JA. Light transmission through all-ceramic dental materials: a pilot study. J Prosthet Dent. 2004;91(5):441-6. https://doi.org/10.1016/j.prosdent.2004.02.019.

7. Braga RR, Cesar PF, Gonzaga CC. Mechanical properties of resin cements with different activation modes. J Oral Rehabil. 2002;29(3):257-62. https://doi.org/10.1046/j.1365-2842.2002.00821.x.

8. Calgaro PA, Furuse AY, Correr GM, Ornaghi BP, Gonzaga CC. Influence of the interposition of ceramic spacers on the degree of conversion and the hardness of resin cements. Braz Oral Res. 2013;27(5):403-9. https://doi.org/10.1590/ S1806-83242013000500004.

9. Faria-E-Silva A, Boaro L, Braga R, Piva E, Arias V, Martins L. Effect of immediate or delayed light activation on curing kinetics and shrinkage stress of dual-cure resin cements. Oper Dent. 2011;36:196-204. https://doi. org/10.2341/10-153-L.

10. Faria-E-Silva AL, Pfeifer CS. Effectiveness of high-power LEDs to polymerize resin cements through ceramics: an in vitro study. J Prosthet Dent. 2017;118(5):631-6. https://doi.org/10.1016/j.prosdent.2016.12.013.

11. Tanoue N, Koishi Y, Atsuta M, Matsumura H. Properties of dual-curable luting composites polymerized with single and dual curing modes. J Oral Rehabil. 2003;30:1015-21. https://doi.org/10.1046/j.1365-2842.2003.01074.x.

12. Faria-e-Silva AL, Fabião MM, Arias VG, Martins LR. Activation mode effects on the shear bond strength of dual-cured resin cements. Oper Dent. 2010;35:515-21. https://doi.org/10.2341/10-051-L.

13. Lu H, Powers JM. Color stability of resin cements after accelerated aging. Am J Dent. 2004;17:354-8.

14. Kilinc E, Antonson SA, Hardigan PC, Kesercioglu A. Resin cement color stability and its influence on the final shade of all-ceramics. J Dent. 2011;39:e30-6. https://doi.org/10.1016/j.jdent.2011.01.005.

15. Almeida JR, Schmitt GU, Kaizer MR, Boscato N, Moraes RR. Resin-based luting agents and color stability of bonded ceramic veneers. J Prosthet Dent. 2015;114:272-7. https://doi.org/10.1016/j.prosdent.2015.01.008.

16. Archegas $L R$, Freire A, Vieira S, Caldas DB, Souza EM. Colour stability and opacity of resin cements and flowable composites for ceramic veneer luting after accelerated ageing. J Dent. 2011;39:804-10. https://doi.org/10.1016/j. jdent.2011.08.013.

17. Leal CL, Queiroz A, Foxton RM, Argolo S, Mathias P, Cavalcanti NA. Water sorption and solubility of luting agents used under ceramic laminates with different degrees of translucency. Oper Dent. 2016;41:e141-8. https://doi. org/10.2341/15-201-L.

18. Fróes-Salgado NR, Silva LM, Kawano Y, Francci C, Reis A, Louguercio AD. Composite pre-heating: effects on marginal adaptation, degree of conversion and mechanical properties. Dent Mater. 2010;26(9):908-14. https://doi. org/10.1016/j.dental.2010.03.023.

19. Deb S, Di Silvio L, Mackler HE, Millar BJ. Pre-warming of dental composites. Dent Mater. 2011;27(4):e51-9. https://doi. org/10.1016/j.dental.2010.11.009.

20. Gresnigt MMM, Özcan M, Carvalho M, Lazari P, Cune MS, Razavi P, Magne P. Effect of luting agent on the load to failure and accelerated-fatigue resistance of lithium disilicate laminate veneers. Dent Mater. 2017;33:1392-401. https ://doi.org/10.1016/j.dental.2017.09.010.

21. CIE (Commission Internationale de l'Eclairage). Colorimetry—technical report. 3rd ed. Vienna: CIE Pub; 2004.

22. Johnston WM, Ma T, Kienle BH. Translucency parameter of colorants for maxillofacial prostheses. Int J Prosthodont. 1995;8:79-86.

23. Salgado VE, Rego GF, Schneider LF, Moraes RR, Cavalcante LM. Does translucency influence cure efficiency and color stability of resin-based composites? Dent Mater. 2018;34(7):957-66. https://doi.org/10.1016/j.dental.2018.03.019.

24. Spazzin AO, Guarda GB, Oliveira-Ogliari A, Leal FB, Corre-Sobrinho L, Moraes RR. Strengthening of porcelain provided by resin cements and flowable composites. Oper Dent. 2016;41(2):179-88. https://doi.org/10.2341/15-025-L.

25. Ilie N. Transmitted irradiance through ceramics: effect on the mechanical properties of a luting resin cement. Clin Oral Investig. 2017;21(4):1183-90. https://doi.org/10.1007/s00784-016-1891-3. 
26. Sulaiman TA, Abdulmajeed AA, Donovan TE, Ritter AV, Lassila LV, Vallittu PK, Närhi TO. Degree of conversion of dualpolymerizing cements light polymerized through monolithic zirconia of different thicknesses and types. J Prosthet Dent. 2015;114(1):103-8. https://doi.org/10.1016/j.prosdent.2015.02.007.

27. Lee SY, Cho CB, Koak JY, Yang SE. The effect of zirconia thickness and curing time on shear bond strength of dual cure resin cement. Dent Mater J. 2016;35(1):132-7. https://doi.org/10.4012/dmj.2015-181.

28. Hardy CM, Bebelman S, Leloup G, Hadis MA, Palin WM, Leprince JG. Investigating the limits of resin-based luting composite photopolymerization through various thicknesses of indirect restorative materials. Dent Mater. 2018;34(9):1278-88. https://doi.org/10.1016/j.dental.2018.05.009.

29. Lucey S, Lynch CD, Ray NJ, Burke FM, Hannigan A. Effect of pre-heating on the viscosity and microhardness of a resin composite. J Oral Rehabil. 2010;37(4):278-82. https://doi.org/10.1111/j.1365-2842.2009.02045.x.

30. Rickman LJ, Padipatvuthikul P, Chee B. Clinical applications of preheated hybrid resin composite. Br Dent J. 2011;211:63-7. https://doi.org/10.1038/sj.bdj.2011.571.

31. Daronch M, Rueggeberg FA, De Goes MF. Monomer conversion of pre-heated composite. J Dent Res. 2005;84(7):663-7. https://doi.org/10.1177/154405910508400716.

32. Al-Ahdal K, Silikas N, Watts DC. Rheological properties of resin composites according to variations in composition and temperature. Dent Mater. 2014;30(5):517-24. https://doi.org/10.1016/j.dental.2014.02.005.

33. Ribeiro R, Salgado VE, Cavalcante LM, Schneider LF. Conversion and color stability of luting agents for aesthetic rehabilitations. Dent Mater. 2017;3(S1):e71. https://doi.org/10.1016/j.dental.2017.08.143.

\section{Publisher's Note}

Springer Nature remains neutral with regard to jurisdictional claims in published maps and institutional affiliations.

\section{Submit your manuscript to a SpringerOpen ${ }^{\circ}$ journal and benefit from:}

- Convenient online submission

Rigorous peer review

- Open access: articles freely available online

- High visibility within the field

Retaining the copyright to your article

Submit your next manuscript at $\gg$ springeropen.com 